\title{
Psicólogo Hospitalar da Cidade de Recife - PE
} Formação e Atuação

City of Recife- PE's hospital psychologist:

Underground education and performance

Adriana Karla Jeronimo Marques de Sá, Alexsandra Elenir Nunes Lima, Íris Maria da Silva Marques dos Santos \& Lídio Clemente

Centro de Psicologia Hospitalar e Domiciliar (CPHD)
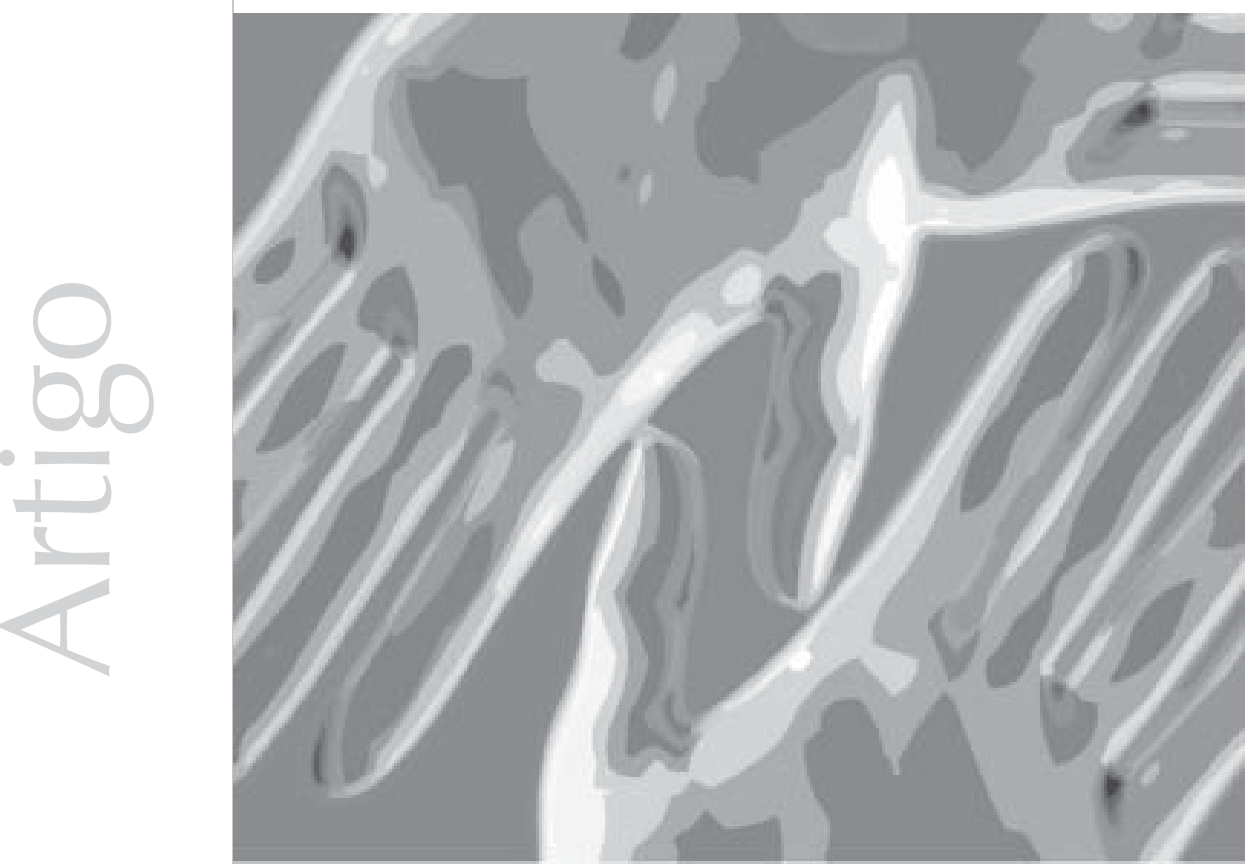


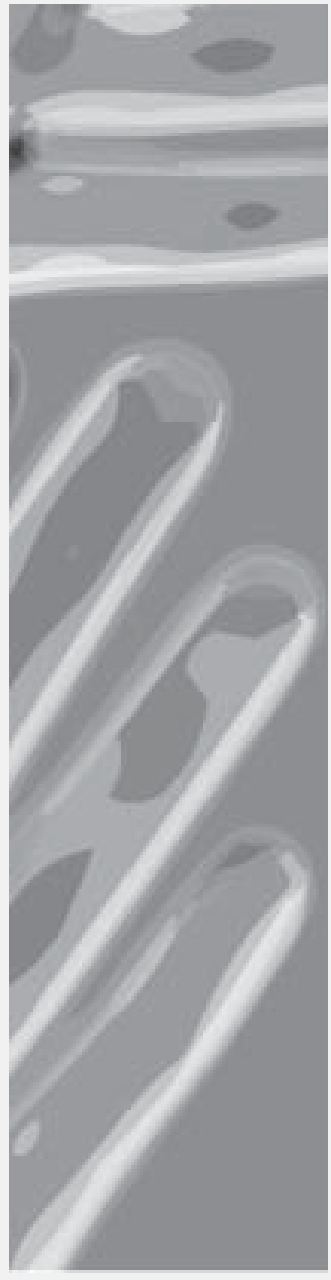

Resumo: Identifica-se, como objeto deste estudo, a descrição do perfil do psicólogo hospitalar da cidade de Recife, enfatizando a sua formação e atuação, partindo da premissa que a formação acadêmica não oferece os subsídios necessários para a prática. Elaborou-se, para tanto, um questionário com questões fechadas, aplicado a 51 profissionais que trabalhavam em hospitais. Os resultados indicaram que a formação acadêmica não foi considerada suficiente para a atuação em hospital. Verificou-se, ainda, uma escassez de pesquisas e, em conseqüência, de publicações, o que deve refletir a própria formação, que não leva o aluno a articular profissão com pesquisa.

Palavras-chave: psicólogo hospitalar, formação, atuação.

Abstract: This research aims to show the profile of the hospital psychologist in Recife, emphasizing his/her underground education and performance, taking into account the fact that academic education doesn't offer enough subsidy for this practice. A questionnaire with multiple choice was made and applied to 51 professionals who have worked at hospitals. The results showed that academic studies weren't good enough to give professionals a basis for the work in hospitals. Due to the lack of research and publications the level of education doesn't help the students link their profession and research.

Key words: hospital psychologist, underground education, performance.
A Psicologia tem importância em todas as situações relacionadas à saúde do ser humano, exercendo, destarte, o psicólogo a sua profissão tanto no âmbito da prevenção como no âmbito do tratamento, sendo que, segundo Bleger (1984), a prevenção tem um caráter primário, e o tratamento, um caráter secundário.

De acordo com Campos (1995), "o trabalho do psicólogo hospitalar seria tanto no sentido de uma prevenção primária, através de medidas como educação e reorganização social, ocupando-se de problemas ou situações presentes que podem levar à doença ou favorecer o surgimento da doença, como também na área de prevenção secundária" (p. 65), ou seja, em situações de crise, na tentativa de evitar que os problemas venham a tornar-se crônicos.

O psicólogo, na sua prática hospitalar, busca manter o relacionamento humano saudável, e isso envolve o diálogo com o paciente e seus familiares e a equipe de saúde, funcionando, assim, como um facilitador da comunicação entre eles. Para tanto, além do bom senso, é necessário que se tenha domínio de recursos psicológicos, técnicos e científicos. Por se tratar o contexto hospitalar de uma realidade em que o paciente se encontra em crise, a abordagem mais adequada é a psicoterapia breve de apoio. 
Ao ingressar no hospital, o paciente passa a ser representado por um número, tal como consta no prontuário e, freqüentemente, tem ainda de usar a vestimenta do hospital. Existe, além disso, o medo de morrer ou de sofrer as seqüelas físicas decorrentes da doença. Tantas modificações, de acordo com Campos (1995), podem suscitar no paciente regressões emocionais, negação da realidade ou apego afetivo a funcionários do hospital, ou mesmo dependência do pessoal. Tais mecanismos de defesa requerem um conhecimento mais profundo das emoções do indivíduo, parte do arcabouço teórico e prático do psicólogo.

A constatação, por parte da equipe de saúde, da importância das emoções, que influenciam na eficácia do tratamento das doenças, bem como da ênfase na humanização do hospital, serviu para suscitar um clima propício à inserção do profissional de Psicologia no hospital. Para Romano (1999), "os médicos e os profissionais de saúde deram-se conta de que há um lado 'obscuro', 'inconsciente', que complica evoluções e reduz a terapêutica prevista" (p. 26).

Além da importância dos profissionais de saúde (equipe) para o ingresso do psicólogo no hospital, a mídia também exerceu um papel fundamental, no sentido de desmitificar a figura negativa do psicólogo diante da população, que passou a reconhecer que o emocional pode ser responsável pelo surgimento das doenças.

Lancetti (1986) afirma que a própria prática do psicólogo no hospital é que foi delimitando o campo. "Assim, a intervenção do psicólogo foi saindo da teoria e do papel. A partir disso, aponta que o psicólogo, além de diagnosticar e classificar, tem de entender, compreender o que está envolvido na queixa e no sintoma, na patologia" (in Campos, 1995, p. 67).

Diante do exposto, é possível verificar a relevância do ingresso do psicólogo no hospital. Mas, e a formação recebida pelo profissional, oferece os subsídios necessários para que ele possa enfrentar essa realidade?
A literatura a respeito da formação e atuação do psicólogo é unânime ao afirmar que o modelo vigente para o desempenho da profissão é direcionado à prática clínica de consultório, o que não se aplica às instituições (por exemplo, Duran, 1994; Francisco e Bastos, 1992; Gomide, 1988; Romano, 1999). Esse modelo, por sua vez, reflete o currículo mínimo de Psicologia, tendo em vista que não sofreu modificações significativas desde a sua elaboração, no início dos anos 60, e concebe o psicólogo como "avaliador de características psicológicas e voltado para a intervenção clínica remediativa (Conselho Federal de Psicologia, 1994, p.1). Baseia-se tal concepção no modelo médico que, por enfatizar o indivíduo nas suas características individuais, não é suficiente para abordá-lo no seu contexto socioeconômico e cultural.

No que se refere à atuação do psicólogo em hospitais, de acordo com Romano (1999), esta teve início, no Brasil, na década de 50, consistindo o seu trabalho, basicamente, no "transporte do consultório para dentro do hospital". No entanto, a própria dinâmica e as peculiaridades desse trabalho foram exigindo dos profissionais uma nova postura, teórica e prática, mais voltada para atender à nova demanda. Mas, infelizmente, não se deu essa mudança de forma plena, levando-se em conta que sempre há resistência por parte de alguns; predomina ainda hoje, nos postos de saúde, o modelo de atendimento de consultório, conforme foi verificado por Cavalari e cols. (1992, in Romano, 1999), no II Congresso Nacional de Psicólogos. Observaram também uma falta de referencial teórico para a prática, tendo em vista que a maioria dos psicólogos tinha a psicanálise como base teórica e outros nem sequer tinham linha definida.

Para Francisco e Bastos (1992), "é limitada a percepção das possibilidades de atuação do psicólogo, quando este é visto quase como sinônimo de psicoterapeuta; tal percepção reflete-se, inclusive, nas expectativas e 
demandas apresentadas pelos estudantes aos cursos de Psicologia" (p. 211).

Luzio (1989), in Romano (1999), também ressalta a questão de o aluno enxergar o consultório como único percurso de atuação, consistindo essa prática um "mito" para o exercício da Psicologia; ressalta, dentre os motivos, os mais relevantes, como:

- O fato de ingressar o aluno no curso achando que vai encontrar nele a resolução para os seus problemas;

O desejo de se tornar um profissional liberal;

- A ilusão de que irá ganhar muito dinheiro.

Conforme Romano (1999), a Universidade, por sua vez, reforça as expectativas do aluno à medida que não busca reunir dados sobre $\mathrm{o}$ mercado de trabalho e os diversos campos de atuação do psicólogo, visando a apresentar ao aluno e a prepará-lo, assim, para enfrentar o mercado de trabalho. Francisco e Bastos (1992), remetendo a Botomé (1988), corroboram a visão de Romano (op. cit.) quando afirmam que "as deficiências do processo de formação fortalecem ou direcionam os alunos para 'papéis, conhecimentos e tecnologias mais tradicionais e mais difundidos ou populares (e nem sempre os mais sólidos) em relação à atuação do psicólogo'" (p. 211). Percebem, ainda, transformações na atuação do psicólogo, oriundas da prática profissional, que eles denominam de "movimentos muitas vezes sutis que, imperceptivelmente, vão gerando novos modelos, nova 'cara' para o conjunto de serviços que o psicólogo presta à sociedade" (idem, p. 211). Essas transformações ocorrem devido às pressões advindas de mudanças socioeconômicas e culturais, encontrando-se a Psicologia da Saúde (dentro dela, a prática hospitalar) inserida nesse movimento, como uma área emergente que trouxe contribuições significativas para mudanças estruturais no campo profissional.

Entretanto, Francisco e Bastos (1992) verificam uma resistência a tais inovações no que se refere à formação. Segundo Weber e Carraher (1992), in Francisco e Bastos (1992), "o currículo vigente no Brasil não reflete o estado atual da Psicologia como ciência e como profissão. Constatam-se defasagens patentes entre o que aqui é ensinado e o que é produzido nos grandes centros intelectuais" (pp.211-213).

Segundo Rosas, Rosas e Xavier (1988), a análise da formação, ao longo dos anos, mostrou que os psicólogos que haviam se formado durante os anos 80 são os mais insatisfeitos com os conhecimentos obtidos na Faculdade.

Carvalho (1984), in Gomide (1988), ao pesquisar psicólogos recém-formados, relata que $66 \%$ dos entrevistados indicaram a área clínica como a área de atuação em que foram mais bem preparados durante o curso de graduação. "Mais da metade (54\%) dos sujeitos afirmou ter adquirido consciência de problemas éticos na prática da Psicologia, durante o curso, porém uma parcela equivalente (52\%) disse que teve insuficiente conhecimento sobre a realidade socioeconômica na qual o psicólogo atua e também pouco aprendeu sobre o papel social desse profissional" (p. 74). Diante de tal constatação, o autor afirma que a formação não prepara o profissional para construir a Psicologia, e, sim, repeti-la. Matos (1988), Francisco e Bastos (1992) e Duran (1994) concordam com esse autor quando concebem que o modo como se dá a formação leva os alunos a serem passivos diante do processo ensino-aprendizagem.

Para Matos (1988), as disciplinas do curso de Psicologia são basicamente voltadas para a 
é fundamental que haja uma integração entre formação teórica e prática bem como formação cientifica e profissional, embora, atualmente, a literatura relacionada à formação tenha constatado que a produção e a formação em Psicologia, no Brasil, é mínima, acarretando essa falta de engajamento em pesquisa um verdadeiro empecilho tanto para o

desenvolvimento do profissional como para o próprio avanço da profissão.

Duran teoria. Tanto para a referida autora como para Francisco e Bastos (op.cit), no que concerne ao processo ensino-aprendizagem, o sujeito não é levado nem mesmo a analisar, refletir sobre o conteúdo. Essa realidade abrange o profissional, que se encontra, por sua vez, desqualificado para atender à demanda que o mercado de trabalho oferece, por exemplo, ligada à população carente, que não pode freqüentar o consultório particular. A esse respeito, Silva (1984), in Gomide (1998), enfatiza que "os psicólogos são profissionais com uma formação técnica; preocupados muito mais com a doença do que com a saúde; que enfatizam e investem no indivíduo que está sofrendo e não nas condições ou variáveis que determinam o seu sofrimento (...)" (p.74).

De acordo com Francisco e Bastos (1992) e Duran (1994), é fundamental que haja uma integração entre formação teórica e prática bem como formação científica e profissional, embora, atualmente, a literatura relacionada à formação tenha constatado que a produção e a formação em Psicologia, no Brasil, é mínima, acarretando essa falta de engajamento em pesquisa um verdadeiro empecilho tanto para o desenvolvimento do profissional como para o próprio avanço da profissão.

Essa lacuna, segundo Romano (1999), abrange também a Psicologia hospitalar. A autora chama ainda a atenção para o processo ensino-aprendizagem, onde se verifica que, na maioria das vezes, há um distanciamento da prática por parte do professor (supervisor), conforme se pode observar, no campo da Psicologia hospitalar, nas diversas situações:

“a) professores que nunca trabalharam em hospitais, mas leram ou até desenvolveram pesquisas em questões que envolviam o corpo/ saúde (o que não garante o domínio das particularidades dessa área de atuação); b) professores que destacam o aluno para um hospital mantêm-se à distância porque lá não atuam e que fazem supervisão do caso atendido sem a visão total da realidade da doença, do ambiente, da equipe (...);

c) professores que já trabalhavam em hospital e que, agora, não exercem mais essa atividade, mas dedicam-se ao ensino superior;

c) profissionais recém-formados que, no afã de aumentar a renda, oferecem cursos de extensão universitária aos quais ocorrem alunos ávidos por conhecer esse tipo de tarefa $(\ldots)^{\prime \prime}$ (p.89).

Além das falhas abordadas em relação ao ensino, há falhas na prática do estágio em si no que se refere ao número de horas, por exemplo; há estágios com carga horária de apenas duas horas semanais, em setores do hospital onde não existem profissionais e até mesmo estagiários sem programa. Além disso, torna-se difícil avaliar a qualidade do estágio e da formação profissional, tendo em vista que geralmente só é feita a avaliação do estagiário e nunca a do supervisor ou a do estágio em si (idem, p.89). O aluno, por sua vez, aceita passivamente a situação, tal como fazia na Universidade.

\section{Objetivo}

Considerando que a formação acadêmica não capacita teórica e tecnicamente o profissional para a realidade do hospital, objetiva-se, neste estudo, identificar o perfil do psicólogo hospitalar e, através deste, avaliar a qualificação profissional e a forma como esta interfere em sua atuação em um campo relativamente novo da Psicologia. 


\section{Método}

\section{Amostra}

Esta pesquisa foi composta por 51 psicólogos da cidade de Recife, sendo 48 do gênero feminino e 2 do gênero masculino, com média de idade de 38,85 anos, que responderam, voluntariamente, ao questionário. Destes, um foi excluído, tendo em vista que o profissional respondeu pelas duas instituições hospitalares onde trabalhava, mas não especificou, em algumas questões, a instituição a que se referia nas respostas. É importante enfatizar que não fizeram parte da pesquisa estagiários e voluntários, considerando que estes não mantinham vínculo empregatício com a instituição.

Com relação ao ano de formatura, observouse que 54\% dos entrevistados se formaram entre os anos de 1981 a 1990, sendo 54\% oriundos de universidades privadas, enquanto $46 \%$, de universidades públicas. A maior parte dos entrevistados (76\%) não possui outro curso superior. Verificou-se ainda que os sujeitos têm de 11 a 20 anos de atuação como psicólogo, principalmente nas áreas hospitalar (72\%) e clínica (66\%). Quanto ao tempo de atuação como psicólogo hospitalar, constatou-se que $50 \%$ dos sujeitos têm de 1 a 10 anos de trabalho na área.

\section{Identificação da instituição hospitalar}

Este estudo foi efetuado em 10 hospitais mantidos por órgãos públicos, 3 por órgãos privados e 2 por órgãos mistos (vide anexo I relação dos hospitais que fizeram parte desta pesquisa), perfazendo um total de quinze hospitais, dos quais doze eram gerais, ou seja, tinham mais de três especialidades médicas, enquanto três eram especializados. Vale salientar que a maioria dos hospitais (10) dispunha, com exclusividade, de um setor de Psicologia.

\section{Instrumento}

O instrumento utilizado foi um questionário padronizado, de perguntas com respostas fechadas, que foi preenchido pelos entrevistados, baseado no questionário utilizado na tese de Romano (1987).

Inseriam-se as perguntas em cinco tópicos (identificação, instituição, formação profissional, trabalho, assistência nos diversos setores do hospital e remuneração), referentes à atuação no hospital e à formação acadêmica dos profissionais.

\section{Procedimento}

Inicialmente, efetuou-se um levantamento dos hospitais públicos e privados da cidade de Recife, o que permitiu verificar se nestes havia psicólogos. Em seguida, buscou-se entrar em contato com os profissionais tanto por telefone como pessoalmente. Ao entrar em contato com o profissional, solicitou-se que este respondesse ao questionário ora diretamente com o entrevistador ora sem a presença deste, dependendo da disponibilidade do profissional. Terminada a coleta, analisaram-se quantitativamente os dados a partir do percentual de respostas referentes aos cinqüenta entrevistados.

\section{Resultados e discussão}

Foram computadas as respostas dos respondentes, a partir das quais observaramse as suas porcentagens, fornecendo dados descritivos da sua atuação e da relação desta com a formação acadêmica. Esses dados podem ser verificados na Tabela 1 . 
Tabela 1. Porcentagem das respostas dos psicólogos sobre a sua atuação profissional.

\section{Questões}

Atividades realizadas para aprimorar a formação

Especialização

Aprimoramento como psicólogo hospitalar

Com início do aprimoramento antes de atuar em hospital

Mestrado fora da área de Psicologia hospitalar

Doutorado

\section{Avaliação da formação acadêmica}

Insuficiente

Suficiente

\section{Formas de admissão dos psicólogos}

Concurso público

Nomeação, estágio e à disposição

\section{Carga horária semana}

30 horas

40 horas

20 horas

\section{Avaliação da carga horária}

Suficiente para atender à demanda

Insuficiente para atender à demanda

\section{* Local de atendimento psicológico}

Enfermaria individual

Ambulatório individual

Setores da enfermaria em grupo ou UTI

Ambulatório em grupo e setor de emergência

\section{Atividade extra-hospitalar}

Atendimento em consultório particular

Atendimento em outro hospital

\section{Reuniões técnico-científicas}

Freqüentes reuniões

Ocorrência rara

Porcentagem das respostas (\%)

84

54

72

8

0

90

10

\section{2}

20

66

16

12

\section{2}

36

\section{Profissionais que participam das reuniões}

Médicos e psicólogos

Enfermeiros

Nutricionistas

Acreditam que as reuniões contribuem para interação

Consideram o trabalho do psicólogo valorizado pela equipe 


\begin{tabular}{|c|c|}
\hline \multicolumn{2}{|l|}{ Registros da evolução do paciente } \\
\hline Diretamente no prontuário do paciente & 8 \\
\hline Em arquivo de interesse restrito do serviço da Psicologia & 34 \\
\hline \multicolumn{2}{|l|}{ Assistência no domicílio do paciente } \\
\hline Não realizam & 66 \\
\hline Realizam & 30 \\
\hline Raramente & 22 \\
\hline Freqüentemente & 8 \\
\hline Somente com psicólogos & 24 \\
\hline Junto a outros profissionais & 8 \\
\hline \multicolumn{2}{|l|}{ Inserção do estagiário na assistência psicológica } \\
\hline Afirmam haver estagiários no hospital & 40 \\
\hline Atendem em enfermaria individual & 60 \\
\hline \multicolumn{2}{|l|}{ Atividades dos estagiários } \\
\hline Estudo de caso & 50 \\
\hline Seminários & 46 \\
\hline \multicolumn{2}{|l|}{ Pesquisa } \\
\hline Psicólogos realizam pesquisa no campo da Psicologia & 18 \\
\hline \multicolumn{2}{|l|}{ Remuneração } \\
\hline Mais de $\mathrm{R} \$ 2.000,00$ & 6 \\
\hline Menos de $\mathrm{R} \$ 500,00$ & 20 \\
\hline Afirmam estarem insatisfeitos com a remuneração & 64 \\
\hline
\end{tabular}

* Nesta questão, foi possível obter mais de uma resposta

\section{Formação profissional}

Para aprimorar sua formação como psicólogo, 84\% dos entrevistados fizeram especialização e destes, 54\% aprimorou-se como psicólogo hospitalar, tendo iniciado a formação, na sua maioria, antes de atuar em hospital, com um percentual de $72 \%$. Ressalta-se que apenas $8 \%$ dos profissionais tinham Mestrado, porém não era no campo da Psicologia hospitalar, e nenhum deles tinha Doutorado.

Com relação, ainda, ao aperfeiçoamento, foi possível observar que $90 \%$ dos entrevistados consideram a formação acadêmica insuficiente para atu ar em hospital, enquanto apenas 10\% a consid ra suficiente. Na pesquisa de Romano (1999), a crescente procura por aperfeiç Jamento dá-se pelo fato da constante necessi lade de atualização, o que, em conseqi ência, valoriza a carreira acadêmica. Outro fator também seria a "forma possível para asse gurar conhecimentos para o exercício profissio nal nessa área de trabalho, que carece de estrutura de graduação, isto é, de subsídio teórico e prático compatíveis com o desempenho na área hospitalar" (p.112). 


\section{Atuação}

No que diz respeito à atuação, verificou-se que as formas mais freqüentes de admissão no hospital foram, em primeiro lugar, concurso público $(72 \%)$, tendo em vista que a maior parte dos entrevistados provém de hospitais públicos, seguida de outros (20\%), que foram categorizados como nomeação, estágio e à disposição.

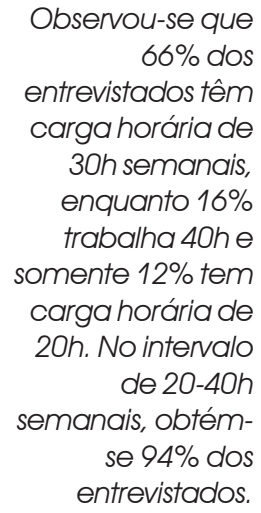

Observou-se que 66\% dos entrevistados têm carga horária de $30 \mathrm{~h}$ semanais, enquanto $16 \%$ trabalha 40 h e somente $12 \%$ tem carga horária de $20 \mathrm{~h}$. No intervalo de 20-40h semanais, obtém-se 94\% dos entrevistados. Esse resultado permite comparar o estudo em questão com o de Romano (1999), tendo em vista que $58,8 \%$ dos entrevistados da pesquisa realizada pela autora trabalham nesse mesmo intervalo de horas semanais.

$\mathrm{Na}$ presente amostra, no que diz respeito ainda à carga horária, 62\% a considera suficiente para atender à demanda de trabalho e $36 \%$ a considera insuficiente. Os dados sobre regime de trabalho indicam que 92\% dos profissionais trabalham como diaristas.

Com relação aos setores do hospital onde o atendimento é realizado com maior freqüência, constatou-se que o setor de maior prevalência de atendimento psicológico no hospital é o da enfermaria individual, com 84\% das respostas, vindo, em seguida, o ambulatório individual, com $74 \%$, e, posteriormente, os setores da enfermaria em grupo e da UTI, com 34\% ambos, bem como do ambulatório em grupo e do setor da emergência, com 30\% das respostas. É importante ressaltar que, nessa questão, foi possível obter mais de uma resposta, uma vez que a maioria dos entrevistados desenvolve seus trabalhos em hospital geral, e, como a demanda é consideravelmente grande, há poucos profissionais para atender uma freqüência diária de 6 a 10 pacientes no ambulatório (22 dos 51 entrevistados) e até 5 pacientes por dia, no setor da enfermaria individual (18 dos 51 entrevistados), de acordo com os dados colhidos neste estudo.

A atividade extra-hospitalar realizada com maior freqüência pelos profissionais é o atendimento em consultório particular (64\%), seguido do atendimento em outro hospital (22\% dos entrevistados).

Os dados referentes às reuniões técnicocientíficas indicam que 58\% dos psicólogos responderam que há freqüentes reuniões técnico-científicas, enquanto 28\% respondeu que elas ocorriam raramente. Os dados apresentam, ainda, que os profissionais que participam freqüentemente das reuniões são os médicos e os psicólogos, com $62 \%$ das respostas; enfermeiros, com 50\%, e os nutricionistas, com $28 \%$. Um fato que se pode verificar no estudo em questão é que 54\% dos entrevistados indicaram que o produto dessas reuniões contribui para a alteração equipe/ médico/ paciente, o que também foi verificado nos achados de Romano (1999), onde se verificou que essas reuniões levaram a um acréscimo significativo da colaboração do psicólogo nas questões em que eram discutidas e definidas condutas de atuação da pesquisa frente ao paciente, considerando tais condutas o trabalho psicológico no que se refere às mudanças comportamentais ou cognitivas do paciente como também sua consolidação, enquanto membro da equipe, em pé de igualdade.

Com relação à valorização do trabalho, 88\% dos entrevistados o consideraram valorizado pela equipe. 


\section{Atividade: assistência nos diversos setores do hospital}

De acordo com os dados pesquisados, os encaminhamentos de pacientes, nos setores de internamento, emergência e UTI são feitos, em primeiro lugar, verbalmente, seguido de um formulário convencional escrito, enquanto, no ambulatório, os encaminhamentos se deram no sentido inverso, sendo o médico o principal agente responsável por tais encaminhamentos, seguido de outro membro da equipe, salientando-se que, diferentemente da assistência no ambulatório, a assistência nos setores de internamento, emergência e UTI é mais dinâmica. Essa dinamicidade de procedimentos médicos e da equipe, em geral em função do paciente, viabiliza maior interação entre os profissionais devido ao fato de circularem, mais freqüentemente, no posto de enfermagem, onde ficam os prontuários do paciente, a que todos os membros da equipe têm acesso.

Esses dados também foram observados por Romano (1999) tanto no setor de ambulatório, onde se verificou que os encaminhamentos, por escrito, são realizados, em primeiro lugar, com $35,1 \%$ das respostas e, em segundo lugar, verbalmente, com $28,8 \%$, como no setor de internamento, o que demonstra que o encaminhamento é feito, em primeiro lugar, de forma verbal, com 49,5\%, e por escrito, em formulário próprio, com 47\%. Ressalta-se que, em ambos os setores, o médico aparece como o principal agente responsável pelo encaminhamento, seguido de outro componente da equipe.

Com relação a este estudo e ao de Romano (1999), embora ambos tenham tido dimensões de abrangência significativamente diferentes, é possível afirmar que há aceitação da inserção do psicólogo hospitalar na equipe, como mediador, nas situações em que há limitação do conhecimento técnico por parte de outros profissionais sobre os aspectos emocionais do paciente e sua direta relação no processo saúde $X$ doença.

No que se refere à prática da evolução do profissional no prontuário do paciente, obtevese que não há uma realização significativa da evolução do paciente, tendo em vista que, dos $42 \%$ dos entrevistados que realizam evolução, apenas $8 \%$ a faz diretamente no prontuário do paciente, enquanto o restante (34\%) a realiza para arquivo de interesse restrito do serviço da Psicologia. Dessa forma, a não socialização do registro para outros membros da equipe sobre os aspectos emocionais do paciente pode dificultar o trabalho integrado. Para Romano (1999), “(...) o registro em prontuário tem a finalidade precípua de resgatar, a qualquer momento, o conteúdo e a forma de intervenção psicológica, tanto para o técnico quanto para os demais membros da equipe" (p. 123.).

\section{Atividade: assistência no domicílio do paciente}

Com relação à assistência no domicílio do paciente, é possível verificar que $66 \%$ dos entrevistados não realizam assistência psicológica no domicílio do paciente, enquanto apenas $30 \%$ realiza atendimento em domicílio. Destes 30\%, 22\% realiza-o raramente e $8 \%$, freqüentemente. Dentre os que realizam visitas domiciliares, tanto raramente quanto freqüentemente, aparecem os que as realizam somente com psicólogos, em um percentual de $24 \%$, e/ou com outro profissional (8\%), e $26 \%$ não responderam. Nessa questão, foi possível mais de uma resposta, considerando que as visitas domiciliares não eram exclusividade da Psicologia, mas, sim, de outros profissionais 
da equipe com o psicólogo, levando, assim, a questionamentos que, de certa forma, apresentam relevância significativa, principalmente quando se coloca a questão do sigilo das informações, que emergem dos atendimentos realizados pela assistência psicológica do hospital.

\section{Atividade: supervisão do estagiário no hospital}

No que diz respeito à atividade de ensino, verificou-se que a inserção do estagiário no processo de trabalho da assistência psicológica apresentou números significativos, pois $40 \%$ dos entrevistados responderam que havia estagiários no hospital (um a quinze estagiários), atuando em todos os setores do hospital. No entanto, os dados da pesquisa mostraram que ainda havia uma certa restrição à presença do estagiário, tendo em vista que $60 \%$ atendia em enfermaria individual, ficando, com isso, a reflexão: a formação do psicólogo hospitalar, na prática, só se restringe à enfermaria individual? Embora essa reflexão leve a outras conjecturas, percebe-se que, provavelmente, limitar o atendimento do estagiário à enfermaria individual tenha sido a solução encontrada pelos psicólogos supervisores para que a demanda atendida em outros setores possa ser realizada de forma mais eficaz, pois, muitas vezes, o espaço físico e os horários não permitem que os estagiários e os profissionais tenham acesso ao atendimento no mesmo setor. Além disso, fazer rodízio dentro do hospital pode levar a uma quebra dos vínculos estabelecidos entre o paciente e aquele que o atende. O tempo de estágio também é outro fator a ser observado, tendo em vista que, em média, é de seis meses a um ano, e, como o tempo do paciente dentro do hospital é um dado significativo para a sua recuperação, deve ser levado em conta na hora de encaminhar o estagiário para os seus atendimentos.

O fator tempo também interfere na supervisão dos estagiários, isso porque, dentre os profissionais que afirmaram haver estagiários no hospital, 46\% realizava supervisão, que tinha duração de duas horas (apresentando maior freqüência, conforme $34 \%$ da amostra). Além disso, as principais atividades executadas pelos estagiários foram estudo de caso (50\%) e seminários (46\%), o que, provavelmente, leva a restringir o número de atendimentos nos diversos setores do hospital.

\section{Atividade: pesquisa}

Com relação à atividade de pesquisa, verificou-se que, de $40 \%$ dos entrevistados que realizam pesquisa, apenas $18 \%$ o fazem somente no campo da Psicologia, o que demonstra que os resultados dessa pesquisa não diferem dos achados da literatura sobre o tema, em que foi possível verificar uma escassez de pesquisas e, em conseqüência, de publicações. Dentre os motivos para a falta de realização de pesquisas na área, provavelmente estejam a falta de incentivo financeiro dentro da instituição $(54 \%$ das respostas) e a grande demanda das atividades de rotina, principalmente devido à lacuna da própria formação do profissional, que não o leva a articular prática e pesquisa. Como enfatiza Francisco e Bastos (1992), “ (...) mais do que não articular ciência-prática, o problema reside na falta de propriedade com que a pesquisa é tratada nos cursos de graduação, o que se traduz na hipertrofia do teórico"... (p.219).

\section{Remuneração}

A referência salarial dos entrevistados foi a 
carga horária, com 56\% das respostas. Vale salientar que 18\% dos entrevistados não responderam à questão e $16 \%$ apontou o funcionalismo público como principal forma de admissão, que, de acordo com os entrevistados, é uma forma de pagamento (salário base) estipulada pelo Estado, comum a todos os funcionários de nível superior. Os dados sobre a referência salarial indicam, na verdade, uma falta de consenso entre os profissionais sobre a referência salarial, o que reflete, provavelmente, uma falta de conhecimento acerca disso. A base salarial dos psicólogos entrevistados tem maior prevalência entre R \$500,00 e R\$1000,00, com $44 \%$ dos entrevistados, enquanto $20 \%$ recebe menos de $R \$ 500,00$ e apenas $6 \%$ ganha acima de $\mathrm{R} \$ 2.000,00$. Devido a essa baixa remuneração, $64 \%$ dos profissionais consideram-se insatisfeitos em relação ao salário .

\section{Considerações finais}

Este estudo permitiu traçar o perfil do psicólogo hospitalar da cidade de Recife, que é constituído, predominantemente, de mulheres jovens, oriundas, na sua maioria, de universidades particulares, atuando precipuamente em instituições públicas (hospital geral), seguido da clínica, com tempo médio de atuação como psicólogo hospitalar de um a dez anos.

Com relação à formação, verificou-se que a maior parte dos profissionais considerou a formação recebida na Universidade insuficiente para atuar em hospital, tendo de recorrer à formação complementar (Especialização) para aprimorar seus conhecimentos. Esse aperfeiçoamento se faz necessário, levando em conta que os cursos universitários, geralmente, preparam o aluno para um modelo clínico de atuação voltado para o consultório. A prática na instituição, por sua vez, exige uma postura técnica e teórica que diverge do modelo tradicional, que aborda o indivíduo nas suas características individuais, isoladas do contexto socioeconômico e cultural, enquanto, no hospital, o profissional se depara com uma dinâmica específica, em que prevalece o trabalho integrado, em equipe, com os familiares e, finalmente, com um paciente em situação de crise.

É importante ressaltar, ainda, no que diz respeito à formação, que nenhum dos entrevistados tinha Mestrado nem Doutorado na área de Psicologia hospitalar, o que pode ser conseqüência da inexistência dessa pós-graduação em Recife, onde prevalecem cursos de especialização em instituições particulares. Observou-se também uma falta de engajamento em pesquisa, o que deve refletir a própria formação, que não leva o aluno a articular a profissão com a pesquisa, constituindo, assim, um entrave para o desenvolvimento tanto do profissional como para o avanço da área. Além dessa lacuna presente na formação, soma-se a isso a crise crônica na saúde devido a uma falta de investimento e ao descaso por parte das autoridades governamentais, devendo esse fato, provavelmente, constituir um dos fatores que contribuem para o não reconhecimento do profissional, que se mostrou insatisfeito com o seu salário. 
Identificação da instituição

Tabela 1 - Relação dos hospitais (públicos, mistos e privados) que fizeram parte deste estudo, seguido do número de profissionais que trabalhavam em cada instituição e do número de questionários respondidos.

\section{Hospitais públicos psicólogos questionários respondidos}

\begin{tabular}{l|l|l}
$\mathrm{H} 1$ & 7 & 4 \\
$\mathrm{H} 2$ & 9 & 6 \\
$\mathrm{H} 3$ & 5 & 3 \\
$\mathrm{H} 4$ & 11 & 8 \\
$\mathrm{H} 5$ & 6 & 6 \\
$\mathrm{H} 6$ & 7 & 7 \\
$\mathrm{H} 7$ & 3 & 2 \\
$\mathrm{H} 8$ & 3 & 2 \\
$\mathrm{H} 9$ & 1 & 1 \\
$\mathrm{H} 10$ & 5 & 1 \\
\hline
\end{tabular}

\section{Hospitais mistos}

$\mathrm{H} 11$

6

3

$\mathrm{H} 12$

4

3

\section{Hospitais privados}

$\mathrm{H} 13$

$\mathrm{H} 14$

$\mathrm{H} 15$

3

Total

72

\begin{tabular}{ll}
\hline 1 & 1 \\
3 & 3 \\
1 & 1 \\
$\mathbf{7 2}$ & $\mathbf{5 1}$
\end{tabular}

* OBS: Dos 51 questionários, um foi anulado, tendo em vista que o profissional respondeu pelas duas instituições hospitalares onde trabalhava, mas não especificou, em algumas questões, a instituição a que se referia nas suas respostas. 


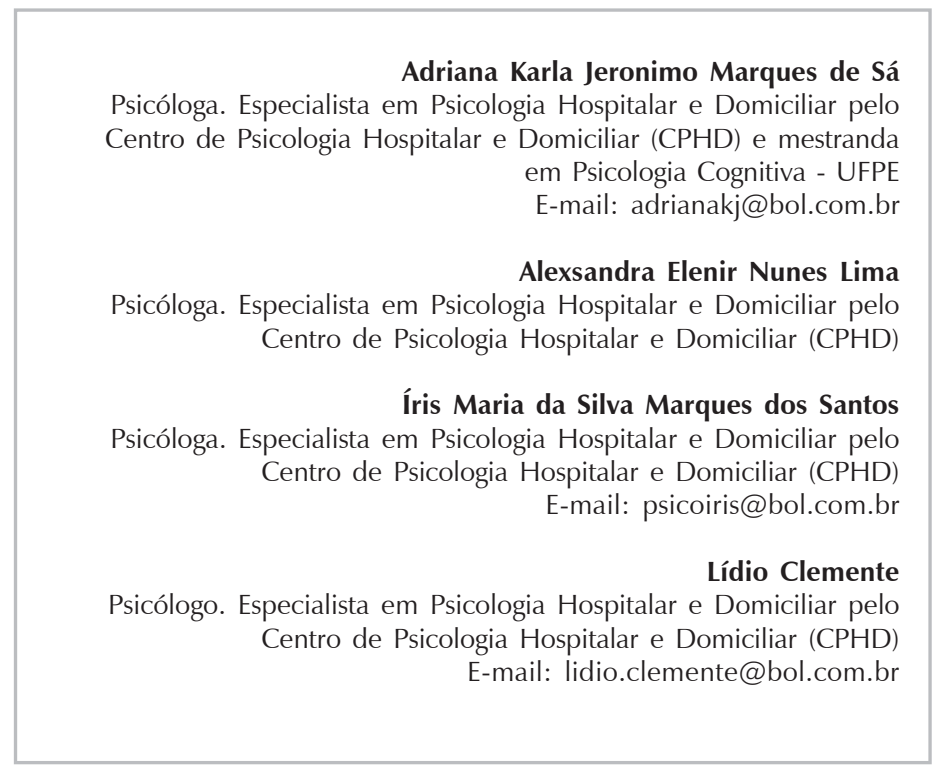

BLEGER, J. Psico-Higiene e Psicologia Institucional. Porto Alegre: Artes Médicas, 1984.

CAMPOS, T.C.P. Psicologia Hospitalar - a Atuação do Psicólogo em Hospitais. São Paulo: Editora Pedagógica e Universitária Ltda, 1995.

Conselho Federal de Psicologia. Psicólogo Brasileiro: Práticas Emergentes e Desafios para a Formação. São Paulo: Casa do Psicólogo, 1994.

DURAN, P. A. Alguns Dilemas na Formação do Psicólogo: Buscando Sugestões para Superá-los. In Conselho Federal de Psicologia. Psicólogo Brasileiro. São Paulo: Casa do Psicólogo, 1994, pp. 273 308.

FRANCISCO, A. L. e BASTOS A. V. B. Conhecimentos, Formação e Prática - o Necessário Caminho da Integração. In Conselho Federal de Psicologia. Psicólogo Brasileiro: Construção de Novos Espaços. Campinas: Atomo, 1992, pp. 211-227.
GOMIDE, P. I. C. A Formação Acadêmica: onde Residem suas Deficiências. In Conselho Federal de Psicologia. Quem é o Psicólogo Brasileiro? São Paulo: EDICON, 1988.

MATOS, M. A. Produção e Formação Científica em Psicologia. In Conselho Federal de Psicologia. Quem é o Psicólogo Brasileiro? São Paulo: EDICON, 1988, pp. 100-122.

ROMANO, B. W. O Psicólogo Clínico em Hospitais. Tese de Doutorado. Universidade Católica de São Paulo, São Paulo, 1987.

Princípios para a Prática da Psicologia Clínica

em Hospitais. Rio de Janeiro: Casa do Psicólogo, 1999. 